\title{
Approach to DRESS Syndrome Associated with Allopurinol Use in a Geriatric Patient
}

\author{
(1) Can Sevinç1', (D) Pınar Tosun Taşar2, (1) Elif Büyükkurt³ \\ 1 Erzurum Atatürk University Faculty of Medicine, Department of Nephrology, Erzurum, Turkey \\ 2Erzurum Atatürk University Faculty of Medicine, Department of Geriatrics, Erzurum, Turkey \\ ${ }^{3}$ Erzurum Atatürk University Faculty of Medicine, Department of Internal Medicine, Erzurum, Turkey
}

\begin{abstract}
Drug rash with eosinophilia and systemic symptoms (DRESS syndrome) is a rare and life-threatening drug-induced hypersensitivity reaction. Here, we present the case of an old man diagnosed with DRESS syndrome after allopurinol therapy. This case highlights the importance of being vigilant for drug toxicity reactions due to allopurinol use that may occur in older adults.
\end{abstract}

Keywords: Allopurinol, drug toxicity, hypereosinophilia

\section{Introduction}

Drug rash with eosinophilia and systemic symptoms (DRESS syndrome) is a rare and life-threatening drug-induced hypersensitivity reaction that presents with skin rashes, hematological abnormalities such as eosinophilia and atypical lymphocytosis, lymphadenopathy, and involvement of internal organs such as the liver, kidney, and lung. Here, we present the case of a 65-year-old man diagnosed with DRESS syndrome after allopurinol therapy. This case highlights the importance of being vigilant for drug toxicity reactions that may occur in older adults due to allopurinol use.

\section{Case Presentation}

A 65-year-old man presented to the emergency department with complaints of generalized itching, low-grade fever, and rash covering his body. He reported that the pruritus started 10 days before the admission. Three days after the onset of pruritus, he had also developed a fever of $39^{\circ} \mathrm{C}$ and rashes starting on the extremities and spreading over his entire body. Systemic inquiry revealed the additional complaint of reduced urine output. On physical examination, his general condition was fair, body temperature was $38.7^{\circ} \mathrm{C}$. Three days after the onset of pruritus, he had developed a fever of $39^{\circ} \mathrm{C}$ and rashes had started on his extremities and spread over the entire body. Facial edema was developed and erythematous maculopapular rashes were observed on his back, trunk, and bilateral upper and lower extremities (Figures 1, 2, and 3). There was no oral mucosal involvement. Other system examinations were normal. The patient's medical history included no known diseases, but the patient reported that he had started allopurinol therapy $(300$ $\mathrm{mg} /$ day) due to hyperuricemia 1 month before the admission. There was no other medication than allopurinol. His family history was unremarkable.

At the time of presentation to the emergency department, his creatinine level was $6.59 \mathrm{mg} / \mathrm{dL}(0.67-1.17 \mathrm{mg} / \mathrm{dL})$, white blood cell count was $23,000 / \mu \mathrm{L}(3,900-10,800 / \mu \mathrm{L})$, neutrophil count was $16,300(2,300-7,600)$, eosinophil count was 3000 (10-500), and leukocytosis, eosinophilia (13\%), and atypical lymphocytes were detected in peripheral blood smear. Complete urinalysis revealed leukocyturia (53;0-4), hematuria (32; 0-3), and no proteinuria. On abdominal ultrasound, kidney size, parenchymal echo, and collecting systems were normal bilaterally.

The patient was admitted to our ward with a preliminary diagnosis of renal failure and DRESS syndrome due to allopurinol

Address for Correspondence: Pınar Tosun Taşar, Erzurum Atatürk University Faculty of Medicine, Department of Geriatrics, Erzurum, Turkey E-mail: pinar.tosun@gmail.com ORCID: orcid.org/0000-0002-2617-4610

Received: Aug 17, 2019 Accepted: Oct 23, 2019

Our case will be presented as an oral presentation in $5^{\text {th }}$ Drug and Treatment Congress 2019.

Cite this article as: Sevinç C, Tosun Taşar P, Büyükkurt E. Approach to DRESS Syndrome Associated with Allopurinol Use in a Geriatric Patient. Eur J Geriatr Gerontol 2019;1(3):107-111

${ }^{\odot}$ Copyright 2019 by the Academic Geriatrics Society / European Journal of Geriatrics and Gerontology published by Galenos Publishing House. 
use. The patient was started on intravenous hydration, $40 \mathrm{mg} /$ day methylprednisolone, and oral antihistamine therapy. The patient's skin lesions began to regress during follow-up and dose of steroid was tapered. The patient received the steroid therapy for a total of 9 days, during this time itchy skin lesions and facial edema and leukocytosis were regressed. C-reactive protein and alanine aminotransferase levels decreased to within normal reference range and the patient's creatinine level decreased to $1.24 \mathrm{mg} / \mathrm{dL}$. Following steroid therapy, the patient's fever gradually fell. The patient's pre-treatment and post-treatment values are summarized in Table 1.

\section{Discussion}

DRESS syndrome is a type IV hypersensitivity reaction. It is characterized by severe skin rashes, fever, lymphadenopathy, hematological abnormalities (eosinophilia or atypical lymphocytes), and internal organ involvement. Although the pathogenesis of DRESS syndrome is not fully known, immunological factors, genetic factors, and factors involved in drug detoxification pathways have been implicated (1). Aromatic anticonvulsants (phenytoin, phenobarbital, carbamazepine) and sulfonamides are the most common causes of DRESS syndrome. Lamotrigine, allopurinol, nonsteroidal anti-inflammatory drugs, captopril, calcium channel blockers, terbinafine, metronidazole, minocycline, and antiretroviral drugs may also cause DRESS syndrome (2). The frequency of allopurinol-induced DRESS

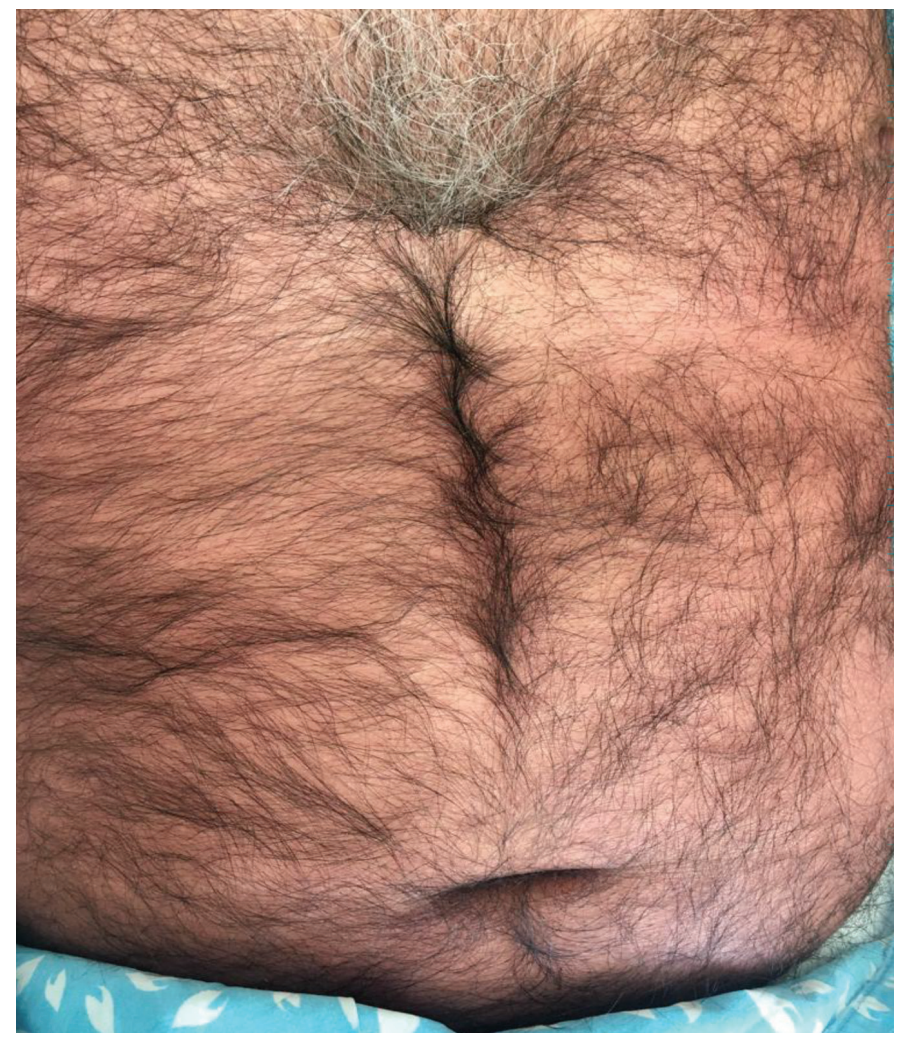

Figure 1. Widespread erythematous maculopapular rashes on the abdomen and chest syndrome is about one in 260 patients treated with this drug (3). Genetic associations between human leukocyte antigen (HLA) associations and drug hypersensitivity may occur. HLA-B*1508, associated with allopurinol induced Stevens-Johnson syndrome and toxic epidermal necrolysis $(4,5)$.

In most patients, the reaction begins 2-6 weeks after initiation of the inducing drug (3). In our patient, the most likely cause of DRESS syndrome was allopurinol, which the patient had started taking 1 month earlier for hyperuricemia.

Currently, the indications for allopurinol therapy are hyperuricemia (gouty arthritis, urate nephropathy, nephrolithiasis) and prophylaxis against urate nephropathy during chemotherapy for neoplastic diseases. Allopurinol

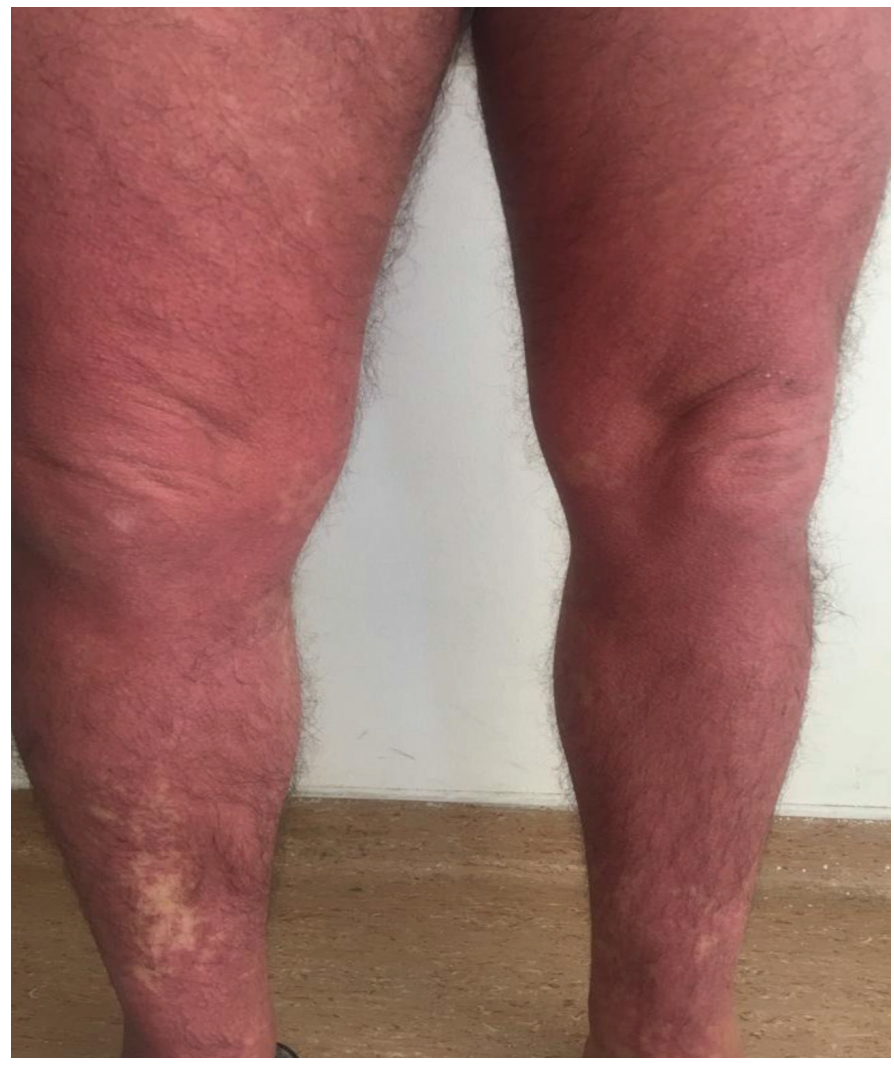

Figure 2. Erythematous maculopapular rashes on both of the patient's lower extremities

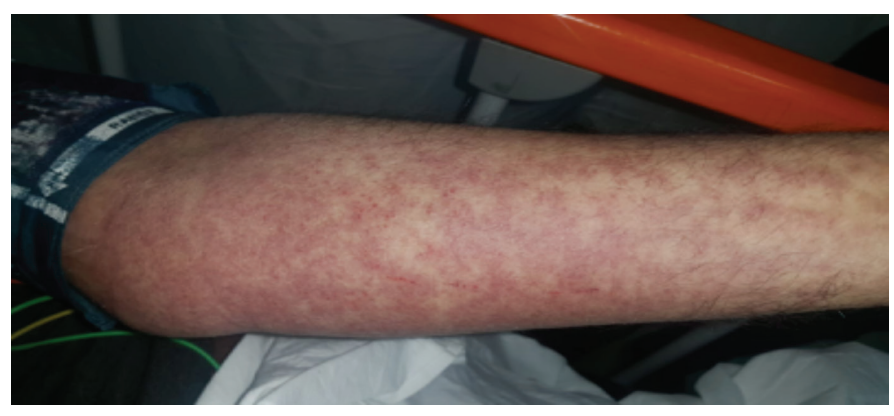

Figure 3. Erythematous maculopapular rash on the patient's upper extremity 
should be used only in these cases and at the appropriate dose. The likely mechanism underlying the development of DRESS syndrome due to allopurinol use is hypersensitivity to allopurinol or oxipurinol (the main metabolite of allopurinol) and immune complex formation with subsequent vasculitis (6).

Oxipurinol accumulation, especially in patients with reduced renal clearance, increases the risk of developing DRESS syndrome. Numerous studies have shown that advanced age, comorbid kidney disease, high-dose drug use, and concomitant use of thiazide diuretics constitute a potential risk for allopurinol-induced DRESS syndrome (7). Fever, malaise, lymphadenopathy, and skin eruptions are the most common symptoms (8).

The rash usually presents in the form of facial and periorbital edema with widespread erythematous eruptions on the trunk and upper extremities. About half of all cases exhibit facial edema (9). Body surface area demonstrates degree of disease involvement and is an important indicator of disease severity. In most cases, over $50 \%$ of the body surface area is erythematous (9). Our patient also had marked facial edema and diffuse erythema on his body (Figures 1, 2, and 3).

At least one internal organ is involved in approximately $90 \%$ of the patients. Two or more organs are involved in 50-60\% of cases, most commonly the liver, kidney, and lung (9-11).

Renal involvement manifests as acute interstitial nephritis and occurs in $10-30 \%$ of DRESS cases, most frequently in those associated with allopurinol $(12,13)$. Renal abnormalities include a moderate increase in creatinine level, low-grade proteinuria, and in rare cases, abnormal urinary sediment containing eosinophils. He had no sign or symptom of other systems involvement.

To help clinicians confirm or exclude the diagnosis of DRESS syndrome, the European Registry of Severe Cutaneous Adverse Reactions (RegiSCAR) developed a scoring system based on clinical features, degree of skin involvement, organ involvement, and clinical course (8). According to this scoring

\begin{tabular}{|l|c|c|c|}
\hline Table 1. Comparison of the patient's laboratory values at presentation with post-steroid therapy & Reference range \\
\hline Laboratory variables & Pre-treatment values & Post-treatment values & $3.9-10.8$ \\
\hline White blood cell count $\left(\times 10^{3} / \mu \mathrm{L}\right)$ & 23.02 & 11.26 & $0.1-6.3$ \\
\hline \% Eosinophil & 13.4 & 13 & $14.4-18.3$ \\
\hline Hemoglobin $(\mathrm{g} / \mathrm{dL})$ & 12.4 & 9.9 & $0-20$ \\
\hline Erythrocyte sedimentation rate & 4 & 5 & $0-5$ \\
\hline C-reactive protein $(\mathrm{mg} / \mathrm{L})$ & 48.1 & 6.89 & $17-43$ \\
\hline Urea (mg/dL) & 142 & 77 & $6-22$ \\
\hline Blood urea nitrogen $(\mathrm{mg} / \mathrm{dL})$ & 66.36 & 35.98 & $1-50$ \\
\hline Alanine aminotransferase $(\mathrm{U} / \mathrm{L})$ & 69 & 30 & $1-50$ \\
\hline Aspartate aminotransferase $(\mathrm{U} / \mathrm{L})$ & 37 & 24 & $1-55$ \\
\hline Gamma-glutamyl transferase $(\mathrm{U} / \mathrm{L})$ & 51 & 40 & $0.67-1.17$ \\
\hline Creatinine $(\mathrm{mg} / \mathrm{dL})$ & 6.59 & 1.24 & $3.5-5.2$ \\
\hline Albumin $(\mathrm{g} / \mathrm{dL})$ & 2.51 & 2.69 & \\
\hline
\end{tabular}

Table 2. RegiSCAR DRESS syndrome scoring system

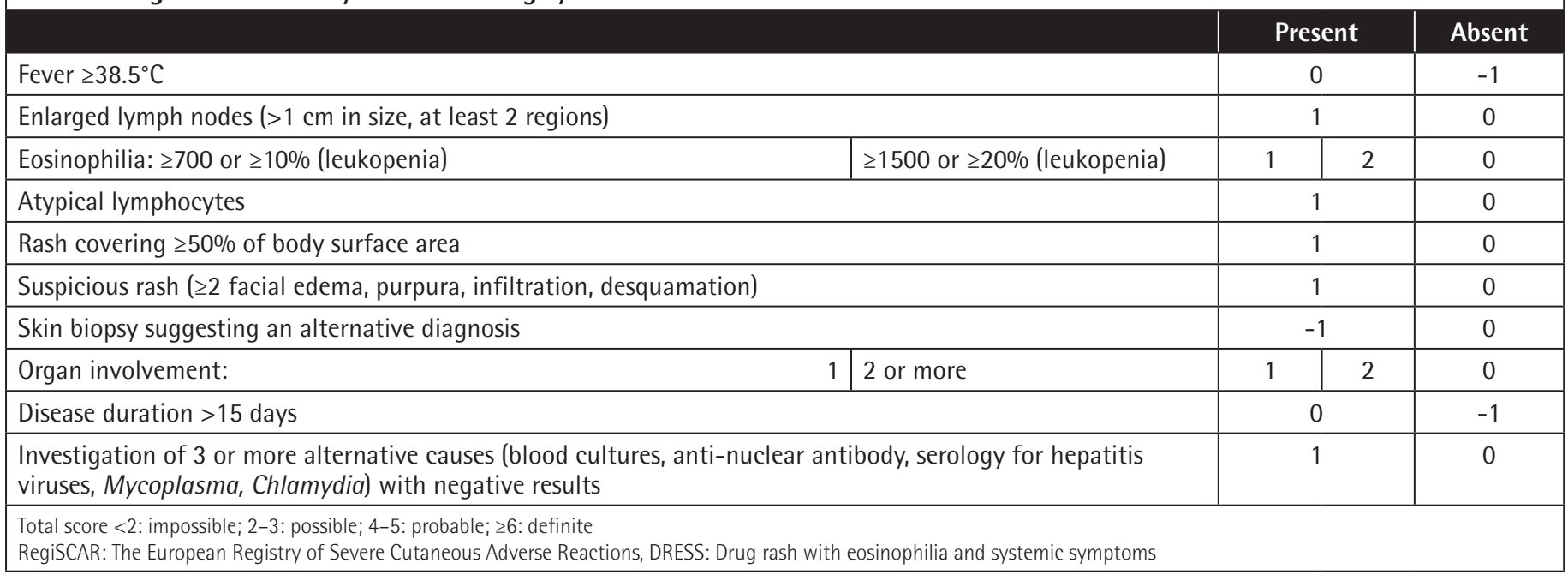


system, DRESS syndrome is classified as definite, probable, or possible (Table 2). Our patient received a RegiSCAR score of 7 (fever, eosinophilia, atypical lymphocytes, involvement of more than $50 \%$ of the body surface area, facial edema, kidney and liver involvement), resulting in a definite diagnosis of DRESS syndrome.

There is no standard treatment for DRESS syndrome. The first step in treatment is to discontinue the suspected drugs. Corticosteroids can dramatically improve clinical condition (1417). Early discontinuation of the drug causing DRESS syndrome will lead to better outcomes. DRESS syndrome can cause lifethreatening multiple organ failure $(18,19)$. The mortality rate is $10 \%$ (16). Intravenous immunoglobulins, plasmapheresis, or a combination of these treatments can be used if symptoms worsen (20).

Systemic corticosteroid therapy is recommended for patients with renal involvement presenting with proteinuria, hematuria, or an increase in creatinine level more than $150 \%$ over baseline. Medium to high doses of systemic corticosteroids are used (e.g., $0.5-2 \mathrm{mg} / \mathrm{kg} /$ day of prednisone or its equivalent). Systemic corticosteroids are administered until clinical improvement and normalization of laboratory parameters are achieved.

The use of systemic corticosteroids for the treatment of DRESS syndrome with severe organ involvement has not been assessed in randomized trials. However, the general consensus among experts is to use systemic corticosteroids in DRESS, particularly for patients with severe organ involvement, especially renal and/or pulmonary involvement.

The optimal dose and duration of corticosteroid therapy is not known. Nevertheless, retrospective observational studies have shown that most DRESS patients with or without severe organ involvement are treated with systemic corticosteroids $(13,17,21,22)$. In our patient, skin lesions resolved and creatinine levels decreased after corticosteroid therapy.

\section{Conclusion}

DRESS syndrome is a condition that presents with fever, rash, elevated liver function markers, and systemic symptoms. When investigating the etiology of sepsis and fever, drug use should be questioned during history-taking and DRESS syndrome should be included in the differential diagnosis. In addition, it should be remembered when initiating allopurinol therapy in patients with chronic kidney disease that they may develop DRESS syndrome. If DRESS syndrome is suspected, the patient should be asked in detail about all drugs they have recently used. The main principles of treatment are early diagnosis, discontinuation of the suspect drug, and supportive care. Favorable outcomes are reported with systemic corticosteroid therapy, especially in severe cases.

\section{Ethics}

Informed Consent: Informed consent was obtained from the patient.

Peer-review: Externally and internally peer-reviewed.

\section{Authorship Contributions}

Concept: C.S., Design: C.S., P.T.T., Data Collection or Processing: C.S., P.T.T., Analysis or Interpretation: E.B., Literature Search: P.T.T., Writing: C.S., P.T.T., E.B.

Conflict of Interest: No conflict of interest was declared by the authors

Financial Disclosure: The authors declared that this study received no financial support.

\section{References}

1. Cardoso CS, Vieira AM, Oliveira AP. DRESS syndrome: a case report and literature review. BMJ Case Rep 2011;2011. pii: bcr0220113898.

2. Tas $\mathrm{S}$, Simonart T. Drug rash with eosinophilia and systemic symptoms (DRESS syndrome). Acta Clin Belg 1999;54:197-200.

3. Markel A. Allopurinol-induced DRESS syndrome. Isr Med Assoc J 2005;7:656660.

4. Lieberman JA, Yunis J, Egea E, Canoso RT, Kane JM, Yunis EJ. HLA-B38, DR4, DQw3 and clozapine-induced agranulocytosis in Jewish patients with schizophrenia. Arch Gen Psychiatry 1990;47:945-948.

5. Vlahov V, Bacracheva N, Tontcheva D, Naumova E, Mavrudieva M, Ilieva P, Michailova A. Genetic factors and risk of agranulocytosis from metamizol. Pharmacogenetics 1996;6:67-72.

6. Sullivan JR, Shear NH. The drug hypersensitivity syndrome: what is the pathogenesis? Arch Dermatol 2001;137:357-364.

7. Kinyó $A 1$, Lakatos $A$, Varga $A$, Gyulai $R$, Varga $E$, Bata-Csörgő $Z$, Kemény L. [Allopurinol-induced hypersensitivity syndrome]. Orv Hetil 2012;153:586-591.

8. Kardaun SH, Sidoroff A, Valeyrie-Allanore L, Halevy S, Davidovici BB, Mockenhaupt M, Roujeau JC. Variability in the clinical pattern of cutaneous side-effects of drugs with systemic symptoms: does a DRESS syndrome really exist? Br J Dermatol 2007;156:609-611.

9. Kardaun SH, Sekula $P$, Valeyrie-Allanore L, Liss $Y$, Chu CY, Creamer D, Sidoroff A, Naldi L, Mockenhaupt M, Roujeau JC; RegiSCAR study group. Drug reaction with eosinophilia and systemic symptoms (DRESS): an original multisystem adverse drug reaction. Results from the prospective RegiSCAR study. Br J Dermatol 2013;169:1071-1080.

10. Lee T, Lee YS, Yoon SY, Kim S, Bae YJ, Kwon HS, Cho YS, Moon HB, Kim TB. Characteristics of liver injury in drug-induced systemic hypersensitivity reactions. J Am Acad Dermatol 2013;69:407-415.

11. Lin IC, Yang HC, Strong C, Yang CW, Cho YT, Chen KL, Chu CY. Liver injury in patients with DRESS: A clinical study of 72 cases. J Am Acad Dermatol 2015;72:984-991.

12. Chen $\mathrm{YC}$, Chiu $\mathrm{HC}$, Chu $\mathrm{CY}$. Drug reaction with eosinophilia and systemic symptoms: a retrospective study of 60 cases. Arch Dermatol 2010;146:13731379.

13. Peyrière $H$, Dereure 0 , Breton $H$, Demoly $P$, Cociglio $M$, Blayac JP, HillaireBuys D; Network of the French Pharmacovigilance Centers. Variability in the clinical pattern of cutaneous side-effects of drugs with systemic symptoms: does a DRESS syndrome really exist? Br J Dermatol 2006;155:422-428.

14. Kumari R, Timshina DK, Thappa DM. Drug hypersensitivity syndrome. Indian J Dermatol Venereol Leprol 2011;77:7-15. 
15. Tas $S$, Simonart T. Management of drug rash with eosinophilia and systemic symptoms (DRESS syndrome): an update. Dermatology 2003;206:353-356.

16. Cacoub P, Musette P, Descamps V, Meyer 0 , Speirs C, Finzi L, Roujeau JC. The DRESS syndrome: a literature review. Am J Med 2011;124:588-597.

17. Um SJ, Lee SK, Kim YH, Kim KH, Son CH, Roh MS, Lee MK. Clinical features of drug-induced hypersensitivity syndrome in 38 patients. J Investig Allergol Clin Immunol 2010;20:556-562.

18. Arellano $F$, Sacristán JA. Allopurinol hypersensitivity syndrome: a review. Ann Pharmacother 1993;27:337-343.

19. Eshki M, Allanore L, Musette P, Milpied B, Grange A, Guillaume JC, Chosidow O, Guillot I, Paradis V, Joly P, Crickx B, Ranger-Rogez S, Descamps V. Twelve- year analysis of severe cases of drug reaction with eosinophilia and systemic symptoms: a cause of unpredictable multiorgan failure. Arch Dermatol 2009;145:67-72.

20. Knowles SR, Shapiro LE, Shear NH. Anticonvulsant hypersensitivity syndrome: incidence, prevention and management. Drug Saf 1999;21:489501.

21. Shalom R, Rimbroth $S$, Rozenman D, Markel A. Allopurinol-induced recurrent DRESS syndrome: pathophysiology and treatment. Ren Fail 2008;30:327-329.

22. Funck-Brentano $E$, Duong $T A$, Bouvresse $S$, Bagot $M$, Wolkenstein $P$, Roujeau JC, Chosidow O, Valeyrie-Allanore L. Therapeutic management of DRESS: a retrospective study of 38 cases. J Am Acad Dermatol 2015;72:246-252. 